\title{
The effects of nano-sized carbon fillers on the physico-chemical, mechanical, and biological properties of polyester nanocomposites
}

\section{Zygmunt Staniszewski, Peter Sobolewski, Agnieszka Piegat, Mirosława El Fray*}

Division of Functional Materials and Biomaterials, Faculty of Chemical Technology and Engineering, The West Pomeranian University of Technology, Szczecin, Al. Piastów 45, 71 311 Szczecin, Poland, *mirfray@zut.edu.pl

\begin{abstract}
Nanocomposites based on poly(ethylene terephthalate-ethylene dilinoleate) (PET-DLA) copolymers of different hard to soft segment ratios (40:60 and 60:40) and three different carbon nanofillers of different aspect ratios (dimensions), as 0D carbon black, 1D multiwalled carbon nanotubes, and 2D graphene, have been prepared in situ during two-stage polymerization. FTIR and NMR spectroscopy was used to characterize the chemical structures of the obtained nanocomposites. Scanning electron microscopy (SEM) indicated very good dispersions of all carbon nanofillers in both polymer matrices. DSC results revealed that the addition of nano-sized fillers eliminated cold crystallization of materials containing $40 \%$ hard segments in polymer matrix. We found that the high aspect ratio, 1D nano-filler (multiwalled carbon nanotubes) strongly nucleated crystallization of materials containing $60 \%$ of hard segments. This nanofiller also yielded the greatest improvement in the Young's modulus as assessed by tensile tests, both at $24^{\circ} \mathrm{C}$ and $37^{\circ} \mathrm{C}$. On the other hand, for nanocomposites containing 2D nanofiller (graphene) we observed reduced bacterial adhesion. Finally, in vitro cytocompatibility tests with L929 murine fibroblasts demonstrated cell growth on all materials except nanocomposites containing carbon nanotubes, where the lowest fibroblast viability was observed.
\end{abstract}

Key words: thermoplastic elastomers, nanocomposites, carbon nanotubes, graphene, carbon black 


\section{Highlights}

- Three carbon nanofillers were used to produce nanocomposites in situ during polymerization

- The chemical structure of the nanocomposites was studied by NMR and IR spectroscopy

- Aspect ratio of nanofiller had a marked effect on thermal and mechanical properties

- Cytocompatibility tests did not show any adverse effect of carbon black/graphene

\section{Graphical Abstract}
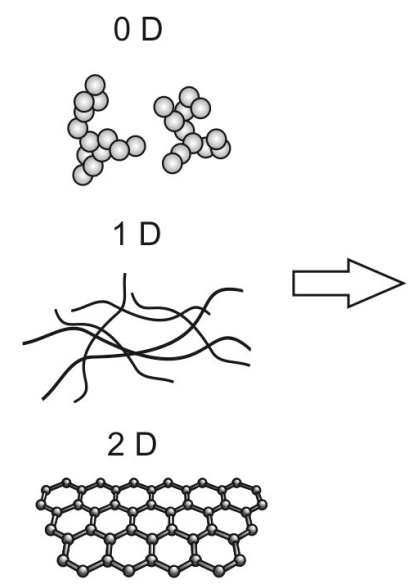

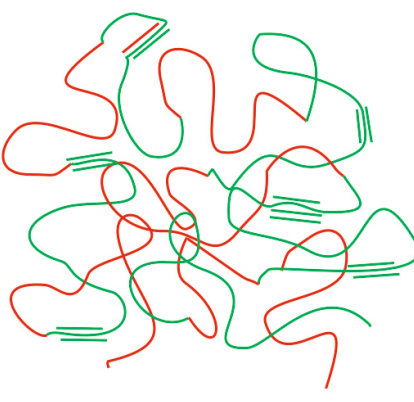

Segmented copolyester PET-DLA
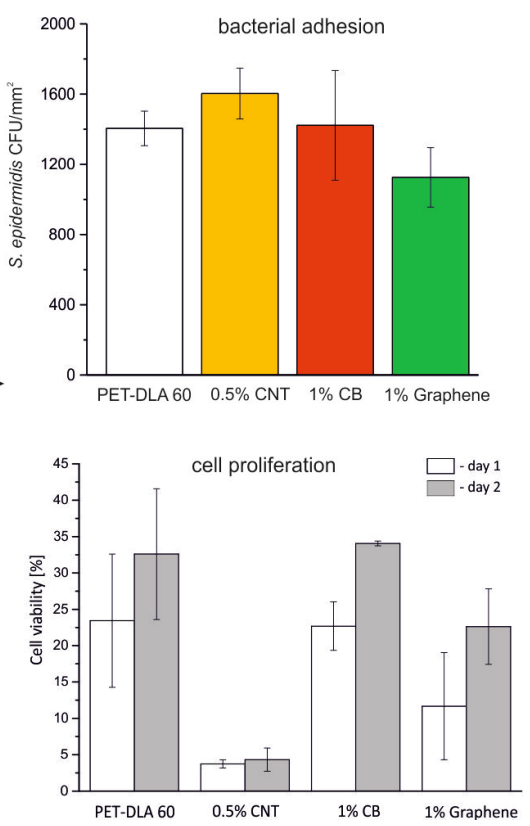


\section{Introduction}

Contemporary engineering materials must be designed to possess multiple, yet specific and desirable features. Biomedical applications are particularly complex and challenging, with the final application of the material driving a number of requirements including mechanical properties, biocompatibility, and/or susceptibility to degradation [1].

Some available polymeric materials for medical applications have a number of limitations related to their chemical structure, leading to strictly defined properties (mechanical, thermal, etc.). In contrast, multiblock copolymers can offer the possibility of tuning a wide range of properties by changing the hard to soft segment ratio-an undeniable advantage [2-3]. For example, poly(ethylene terephthalate) (PET) is an aromatic polyester that exhibits very desirable properties, such as high melting point, very good mechanical properties, and high rigidity [4]. However, modification of PET with bio-based dimeric fatty acid (dilinoleic acid, DLA), yielding PET-DLA multiblock copolyester, can provide enhanced elasticity and improved processing properties, in addition to the very good mechanical properties [5]. These copolymers were recently extensively tested in heart assist devices [6,7], showing good mechanical performance and high bio- and blood compatibility.

Further tuning of properties can be achieved by use of nanofillers and, as a result, polymer nanocomposites have become an important area of research in the field of nanotechnology and biomedicine [8]. The use of various types of carbon nanofillers of different shape (see Table 1), such as carbon black (CB) (spherical objects, aspect ratio $\alpha \sim 1$, 0D), carbon nanotubes (CNT) (tubular systems, aspect ratio $\alpha>>100,1 \mathrm{D})$, and a layered graphene (aspect ratio $\alpha \sim 100,2 \mathrm{D}$ ), can be used to markedly improve the electrical, optical, mechanical, fire resistance or barrier properties of polymeric materials [9-11]. For example, PET/CNT nanocomposites exhibit improved mechanical, thermal and barrier properties 
$[12,13]$. The addition of just $0.4 \mathrm{wt} \%$ multiwalled CNT (MWCNT) can improve the Young's modulus and the yield strength of the PET nanocomposites by approx. $25 \%$ and $15 \%$, respectively [14]. Similarly, the addition of $1 \mathrm{wt} \%$ of functionalized graphene to poly(methyl methacrylate) (PMMA) matrix results in an increase of elastic modulus of about $80 \%$ and elongation at break of about $20 \%$ [15]. On the other hand, carbon black nanofiller is mainly used to enhance electrical conductivity; the addition of 0.1 vol. $\%$ can yield electrically conducting nanocomposites with potential applications as microelectromechanical strain and pressure sensors $[16,17]$.

In this work, we examine the effect of the addition of carbon black nanoparticles, multiwalled carbon nanotubes, and graphene to PET-DLA thermoplastic elastomers with different amounts of hard segments, $40 \mathrm{wt} \%$ or $60 \mathrm{wt} \%$, respectively. All nanocomposites were synthesized via in situ two-stage polymerization and the results are interpreted in terms of carbon filler aspect ratio, dispersion quality, and in relation to the differences in semicrystalline morphology of the PET-DLA $40 \%$ and PET-DLA $60 \%$ matrices. Thus, their potential as next generation materials for heart assist devices will be explored.

\section{Materials and Experimental Methods}

\subsection{Materials}

PET-DLA multiblock thermoplastic elastomers containing $40 \mathrm{wt} \%$ (PET-DLA 40) and $60 \mathrm{wt} \%$ (PET-DLA 60) of hard segments (Wh) of poly(ethylene terephthalate) (PET) and soft segments comprising amorphous fatty acid ester sequences based on dilinoleic acid (DLA), as well as nanocomposites containing $0.05,0.1,0.25,0.5,1 \mathrm{wt} \%$ of graphene (Graphene Supermarket, Grade A0-3, USA), 0.05, 0.1, 0.25, 0.5, 1 wt $\%$ of carbon black (CB) (Cabot, ELFTEX TP, USA) and 0.05, 0.1, 0.25, $0.5 \mathrm{wt} \%$ of MWCNT (CNT) (Nanocyl 7000, Belgium) were synthesized via in situ two-stage polymerization, based on previous work [18, 
19]. For all nanocomposites containing $0.05 \mathrm{wt} \%$ to $0.25 \mathrm{wt} \%$ of nanofiller, dispersions were prepared only in ethylene glycol. For nanocomposites containing $0.5 \mathrm{wt} \%$ to $1 \mathrm{wt} \%$ of nanofiller, dispersions were prepared in both ethylene glycol and dilinoleic acid. Next, two step polymerization was carried out and the obtained nanocomposites were extruded from the reactor under pressure of nitrogen. We were not able to synthesize nanocomposites containing $1 \mathrm{wt} \%$ of MWCNT because the prepared dispersion was so thick and viscous that it was impossible to pour into the reactor during the synthesis. Geometrical characteristics of nanofillers in their pristine form are summarized in Table 1.

Table 1. Geometrical characteristics of used nanofillers.

\begin{tabular}{|c|c|c|}
\hline Filler type & Dimensions & Aspect ratio \\
\hline $\begin{array}{l}\text { OD } \\
\text { Carbon black } \\
\text { (CB) }\end{array}$ & Length $=$ Width $=$ Thickness $\sim 25 \mathrm{~nm}$ & 1 \\
\hline $\begin{array}{l}1 \mathrm{D} \\
\text { Multiwalled } \\
\text { carbon } \\
\text { nanotubes } \\
(\mathrm{CNT})\end{array}$ & $\begin{array}{l}\text { Length } \sim 15 \mu \mathrm{m} \\
\text { Diameter } \sim 15 \mathrm{~nm}\end{array}$ & $\sim 1000$ \\
\hline $\begin{array}{l}\text { 2D } \\
\text { Graphene }\end{array}$ & $\begin{array}{l}\text { Thickness } \sim 12 \mathrm{~nm} \\
\text { Lateral dimensions } \sim 4500 \mathrm{~nm}\end{array}$ & $\sim 375$ \\
\hline
\end{tabular}

\subsection{Characterization techniques}

2.2.1 Fourier transform infrared spectroscopy (FTIR) 
Fourier transform infrared spectroscopy (Spectrometer ATR FT IR Alpha, Bruker) was used to investigate the chemical structure of all obtained materials and to examine the potential of new bond formation between the carbon nanofillers and the PET-DLA matrix. FTIR transmission spectra were recorded between 400 and $4000 \mathrm{~cm}^{-1}$, with $2 \mathrm{~cm}^{-1}$ resolution. Samples were vacuum-dried prior to measurement, and 32 scans were averaged across the spectral range. Polymer and nanocomposites samples were prepared by hot-press compression and discs were cut using a pneumatic punch.

\subsubsection{Nuclear magnetic resonance (NMR)}

Proton nuclear magnetic resonance $\left({ }^{1} \mathrm{H}\right.$ NMR) analysis was performed using a NMR spectrometer (Bruker DPX 400MHz). Nanocomposites samples were prepared by dissolution in a mixture of chloroform and trifluoroaetic acid $\left(\mathrm{CHCl}_{3} / \mathrm{CF}_{3} \mathrm{COOH}(2: 1)\right)$.

\subsubsection{High Resolution Scanning electron microscopy (HR-SEM)}

High resolution scanning electron microscope (Hitachi SU-70) was used to examine the fracture surface of samples. Injection molded samples were frozen in liquid nitrogen, fractured and metal-sputtered with gold-palladium alloy.

\subsubsection{Differential Scanning Calorimetry (DSC)}

The thermal properties of the novel nanocomposites were determined using differential scanning calorimetry method (DSC) (Q100, TA Instruments apparatus). Nanocomposite samples, weighing between 10 and $20 \mathrm{mg}$, were first dried under vacuum at $60^{\circ} \mathrm{C}$ for $24 \mathrm{~h}$. The DSC measurements were carried out in a triple cycle, "heating-coolingheating," over a temperature range from -90 to $300^{\circ} \mathrm{C}$. The heating/cooling rate was $10^{\circ} \mathrm{C} / \mathrm{min}$. The glass transition temperature was determined from the temperature diagrams by the change of the slope of the obtained curves. The melting and crystallization 
temperature were determined as the temperature values corresponding to the maximum of endothermic curve and the minimum of exothermic curve, respectively.

\subsubsection{Mechanical properties}

Tensile tests were performed on Instron 3366 tensile machine with $500 \mathrm{~N}$ load cell to determine Young's modulus, yield point, tensile strength and elongation at break for all of obtained nanocomposites containing various carbon nanofillers in $24^{\circ} \mathrm{C}$ and $37^{\circ} \mathrm{C}$. Tests were performed at a crosshead speed of $200 \mathrm{~mm} / \mathrm{min}$ on injected molded, "dog-bone" shaped samples according to the PN-EN ISO 527 standard. For tests at $37^{\circ} \mathrm{C}$, an environmental chamber was used; however, due to technical limitation of the chamber, tests had to be stopped at $105 \%$ of elongation. As a result, only Young's modulus was calculated, since the machine could not reach tensile strength at break and elongation at break.

\subsubsection{Water contact angle}

The water contact angle was measured by using a KRUSS DSA100 digital goniometer. Contact angle measurements were performed on the surface of degreased materials (prepared by using hot press) by placing a $2 \mu \mathrm{L}$ droplet of deionized water using the automatic dispenser of the goniometer. Contact angle was calculated using Kruss drop shape analysis software (DSA4).

\subsubsection{Surface roughness}

Surface roughness analysis was performed with the Keyence VK9700 Laser Scanning Microscope. Nanocomposite samples were prepared by hot pressing films. The surface roughness of individual materials was evaluated on the basis of roughness coefficient Rq, using Keyence Analyzer software: 


$$
R_{q}=\sqrt{\frac{1}{n} \sum_{i=1}^{n} y_{i}^{2}}
$$

Where: $\mathrm{y}_{\mathrm{i}^{-}}$coarse roughness coordinates.

\subsubsection{Bacterial adhesion assay}

In order to assess the susceptibility of the materials to bacterial colonization, bacterial adhesion assays were performed using model Gram positive (Staphylococcus epidermidis) and Gram negative (Escherichia coli) organisms. Only materials containing the highest amount of nanofiller were tested. Briefly, for each organism, discs were inoculated with 40 $\mu \mathrm{L}$ of 0.5 McFarland inoculum and the bacteria allowed to adhere for 2 hours. After thorough rinsing with phosphate buffered saline (PBS), adherent bacteria were detached via 30 min of vortexing in $1.5 \mathrm{~mL}$ of $0.2 \%$ saponin in PBS and quantified by plating $100 \mu \mathrm{L}$ of serial dilutions and counting colonies after 24 hours. To confirm complete detachment, discs were incubated under brain heart infusion agar for 24 hours. For each material and microorganism, 5 discs were tested and each serial dilution was plated and counted in triplicate.

\subsubsection{In vitro cytocompatibility}

In vitro adhesion and cytocompatibility studies were performed using mouse fibroblasts, L929. Only materials containing the highest amount of nanofiller were tested. Briefly, L929 cells were maintained in T-25 flasks in Dulbecco's MEM (DMEM) medium with high glucose $(4.5 \mathrm{~g} / \mathrm{L})$ and $10 \%$ FBS, $2 \mathrm{mM}$ L-glutamine, $1 \%$ antibiotics (penicillin/streptomycin) at $37^{\circ} \mathrm{C}$ and air atmosphere containing $5 \% \mathrm{CO}_{2}$. For each test material, 4 discs were placed in a 48-well plate and sterilized with ethylene oxide. After degassing, discs were seeded with 30,000 L929 cells in a volume of $300 \mu \mathrm{L}$ of medium. An empty well (tissue culture polystyrene, TCPS) served as a control. After 72 hours of culture, 
medium was exchanged for $200 \mu \mathrm{L}$ medium containing $20 \mu \mathrm{L}$ of $0.15 \mathrm{~g} / \mathrm{L}$ resazurin in PBS. After incubation for 5 hours, fluorescence intensity (ex540/em590) was measured using a Biotek Synergy HTX multifunctional platereader. The measured intensity of fluorescence correlates with the viability of the cells. To confirm cell growth, the cells were maintained in culture and the viability assay was repeated after a further 24 hours.

\subsection{Statistical analysis}

Data is presented as mean \pm standard deviation. Where appropriate, multiple comparison testing was performed via ANOVA followed by Tukey HSD pair-wise or Dunnet's post hoc testing using R software (R Studio).

\section{Results and discussion}

\subsection{Structural characterization}

\subsubsection{FTIR spectroscopy}

Two series of polyester nanocomposites were synthesized and their chemical structure was characterized with FTIR spectroscopy as illustrated in Figure 1. The obtained spectra show bands typical for polyester structure [20]. Absorption band in the region $2800-3300 \mathrm{~cm}^{-}$

${ }^{1}$ corresponds to the stretching vibration of the aliphatic and aromatic $-\mathrm{C}-\mathrm{H}$ bonds. The ester carbonyl bonds can be observed at the wavelength of $1700-1740 \mathrm{~cm}^{-1}$. Two peaks at 1245 $\mathrm{cm}^{-1}$ and the $1100 \mathrm{~cm}^{-1}$ correspond to the oscillations of the $\mathrm{C}-\mathrm{O}$ bond stretching in the ester groups, respectively aromatic and aliphatic. As expected, because the used nanofillers were not functionalized, PET-DLA nanocomposites exhibited similar absorption bands to those of neat PET-DLA copolymer. The lack of significant changes in band positions indicates that the synthesized nanocomposites and reference material have the same structural properties. The minor changes in peak intensities may be caused by slightly different hard to soft 
segment ratios of the polymers, since each material was synthesized via in situ polymerization yielding slightly different polymerization degree.
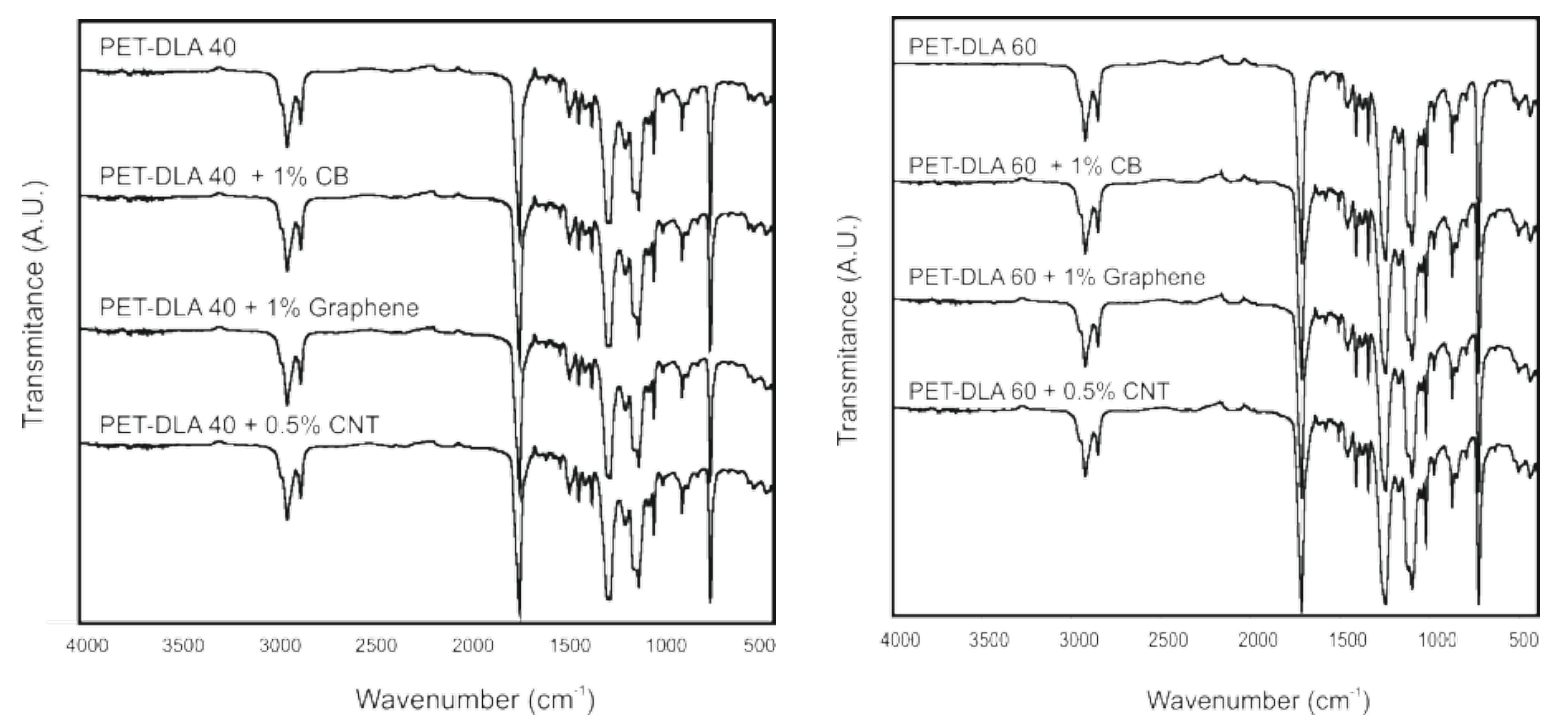

Figure 1. FTIR spectra of PET-DLA 40 nanocomposites (left) and PET-DLA 60 nanocomposites (right).

\subsection{2 ${ }^{1} \mathrm{H}$ NMR spectroscopy}

${ }^{1} \mathrm{H}$ NMR spectra of neat PET-DLA containing $40 \mathrm{wt} \%$ and $60 \mathrm{wt} \%$ of hard segments and prepared nanocomposites containing $0.5 \mathrm{wt} \%$ of CNT, $1 \mathrm{wt} \%$ of $\mathrm{CB}$, and $1 \mathrm{wt} \%$ of graphene are presented in Figure 2 and Figure 3, respectively. 


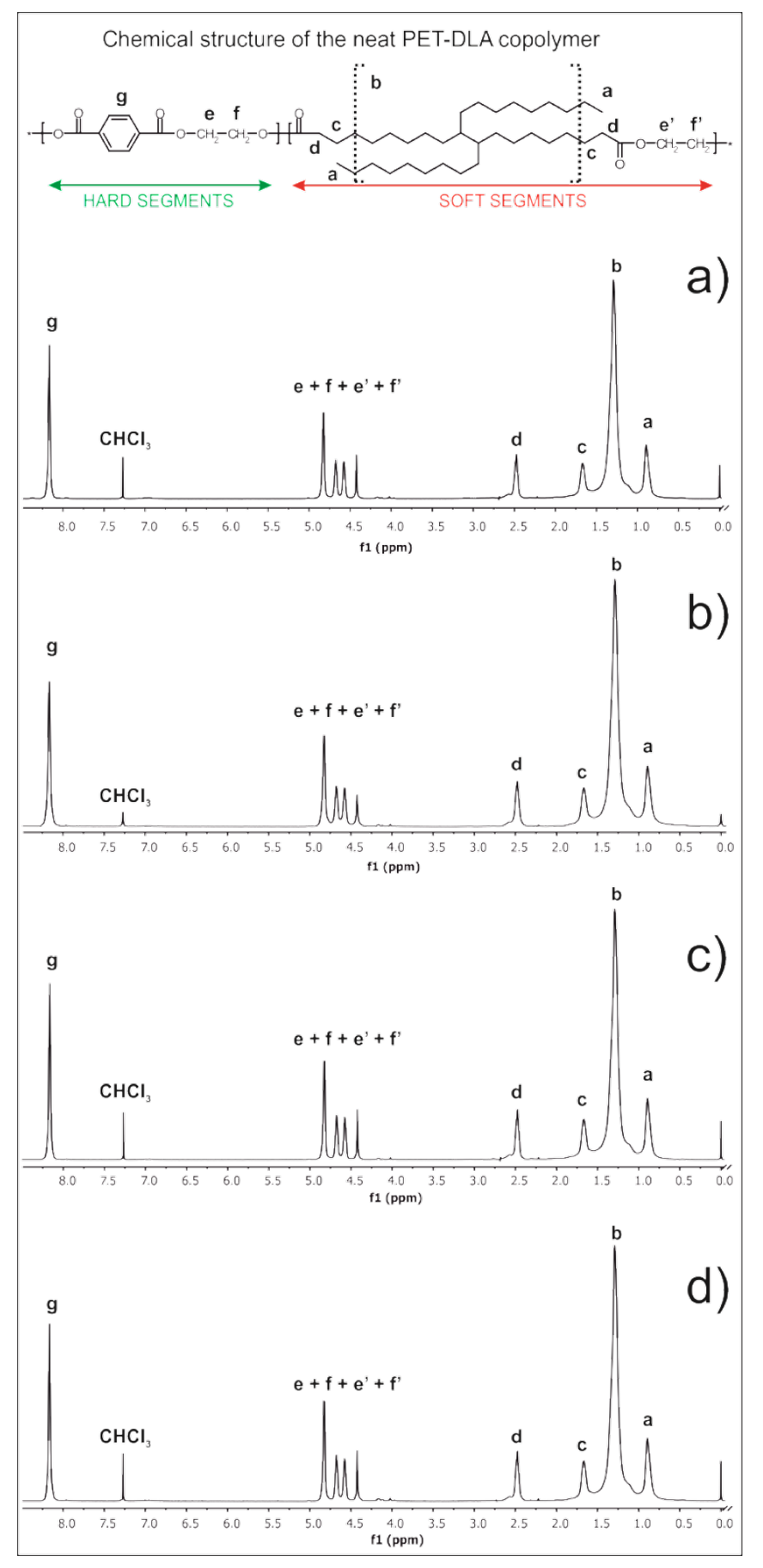

Figure 2. Nuclear magnetic resonance spectroscopy $\left({ }^{1} \mathrm{H}\right.$ NMR) spectra of the neat PET-DLA 40 (a) and obtained nanocomposites containing $0.5 \mathrm{wt} \%$ of CNT (b), $1 \mathrm{wt} \%$ of CB (c) and 1 $w t \%$ of graphene $(d)$. 


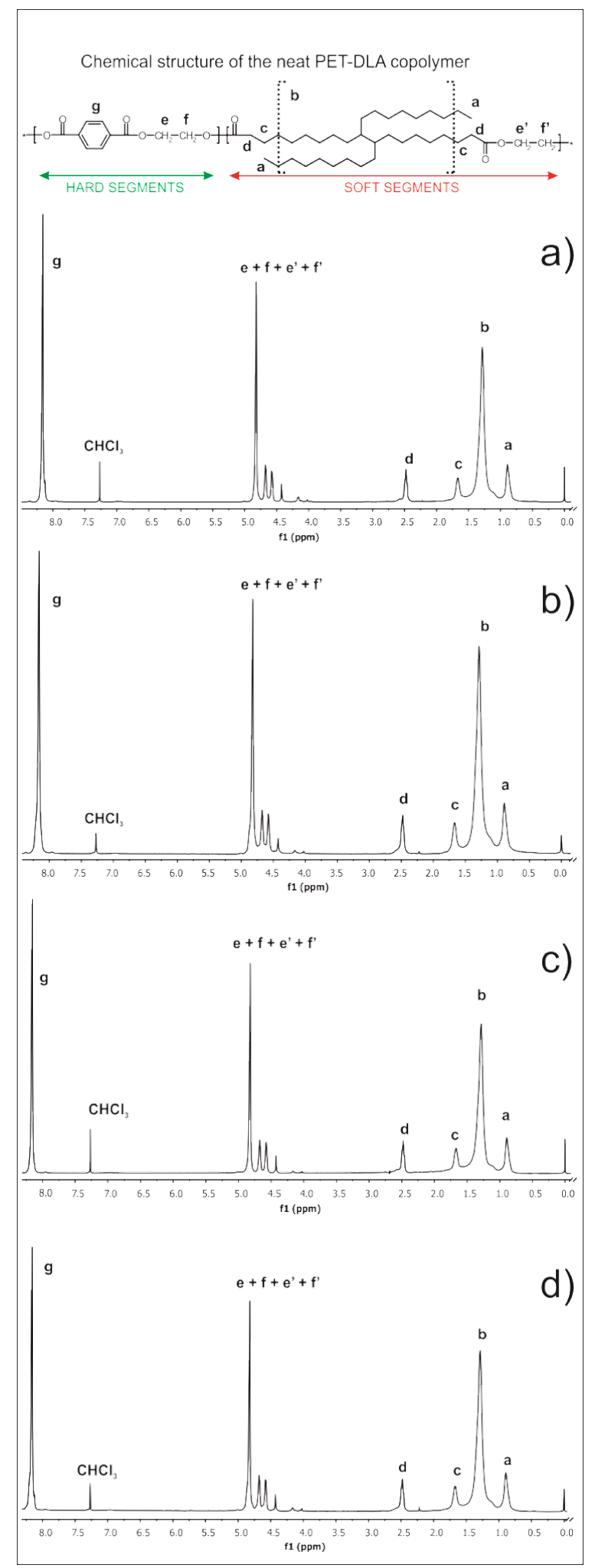

Figure 3. Nuclear magnetic resonance spectroscopy (NMR) spectra of the neat PET-DLA 60 (a) and obtained nanocomposites containing $0.5 \mathrm{wt} \%$ of CNT (b), $1 \mathrm{wt} \%$ of $\mathrm{CB}$ (c) and 1 $w t \%$ of graphene (d). 
As can be seen from Figure 2 and Figure 3, there is no significant difference in between neat PET-DLA copolymers and the obtained nanocomposites for either composition. All spectra show a peak at $8.17 \mathrm{ppm}(\mathrm{g})$ that can be assigned to aromatic ring from PET sequences in hard segments [21]. The peaks at $4.83,4.68,4.58$ and $4.42 \mathrm{ppm}\left(\mathrm{e}+\mathrm{e}^{\prime}+\mathrm{f}+\mathrm{f}^{\prime}\right)$ belong to $-\left(\mathrm{CH}_{2}\right)-\left(\mathrm{CH}_{2}\right)-$ from ethylene glycol sequences. Those peaks are attributed to different methylene protons depending on position in polymer structure. The peak at 4.83 ppm is attributed to the methylene groups between PET hard segments (PEP) (Figure 4a), the peaks at 4.68 and $4.58 \mathrm{ppm}$ are attributed to ethylenedioxyl groups between PET and DLA (hard and soft segments) units (PED) (Figure 4b), and, finally, the peak at 4.58 is attributed to methylene protons of the ethylenedioxyl group between DLA soft segments (DED) (Figure 4c). All possible arrangements of the sequences are shown in Figure 4. The intensities of these peaks depend on the degree of polymerization (DP) and serve as confirmation that obtained the polymers are in fact statistical copolymers. The peak at $2.47 \mathrm{ppm}$ is attributed to methylene groups between DLA and carbonyl group in ester bonds. Finally, the three peaks at $1.67,1.30$ and $0.89 \mathrm{ppm}$ are attributed to methylene groups and ending methyl groups in long DLA chains.

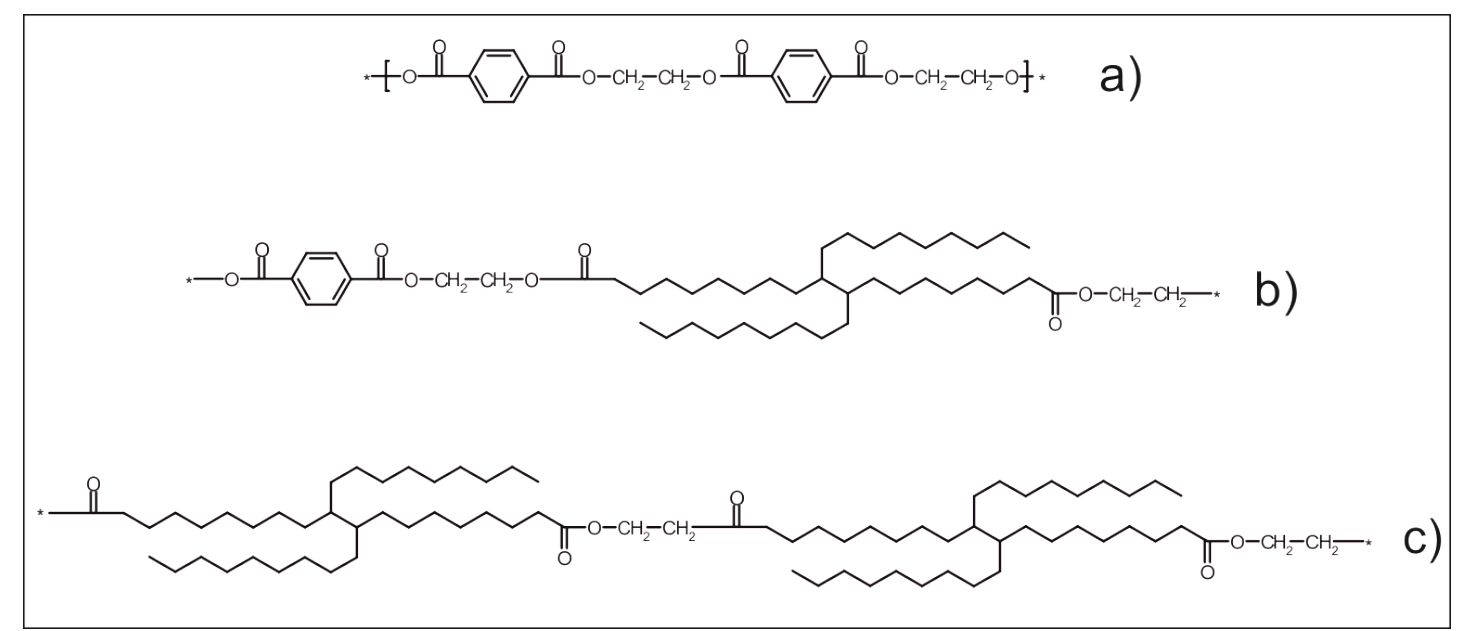

Figure 4. Possible structural unit arrangements. 
Based on the obtained NMR spectra, we calculated the DP of all obtained materials. Since the peak at $8.17 \mathrm{ppm}$ is assigned to 4 protons in the aromatic ring of PET sequences and the peak at $2.47 \mathrm{ppm}$ is attributed to 4 protons in between segments, we can calculate the DP from Equation (2):

$$
D P=\frac{I_{8.17}}{I_{2.47}}
$$

where DP is degree of polymerization, $\mathrm{I}_{8.17}$ is the intensity of peak at $8.17 \mathrm{ppm}$ and $\mathrm{I}_{2.47}$ is the intensity of peak at $2.47 \mathrm{ppm}$.

From the DP, we were also able to calculate weight percentage of hard segments $\left(\% \mathrm{~W}_{\mathrm{h}}\right)$ of obtained materials and compare it with theoretical values using Equation 3:

$$
\% W_{h}=\frac{D P \cdot M_{H}}{D P \cdot M_{H}+M_{S}}
$$

where $\% \mathrm{~W}_{\mathrm{h}}$ is weight percentage of hard segments, DP is the degree of polymerization, $\mathrm{M}_{\mathrm{H}}$ is the molecular weight of hard segment, and $\mathrm{M}_{\mathrm{S}}$ is the molecular weight of soft segments. The results for all obtained materials are presented in Table 2. By knowing the molecular weight of the segments, we were also able to calculate theoretical molar ratio of PEP, PED and DED segments. For PET-DLA $40 \mathrm{wt} \%$ the theoretical calculated molar ratio of those segments is $0.46 / 0.44 / 0.1$, respectively and for PET-DLA $60 \mathrm{wt} \% 0.67 / 0.3 / 0.03$, respectively. Table 1 also shows the values of this molar ratio of PEP, PED and DED segments, as calculated from the NMR spectra for all obtained nanocomposites, confirming that we have synthesized statistical copolymers in all cases. 
Table 2. Degree of polymerization and weight percentage of hard segments calculated from NMR spectra for all synthesized materials.

\begin{tabular}{|c|c|c|c|c|c|c|}
\hline Material & $\begin{array}{l}\text { Theoretical } \\
\text { DP }\end{array}$ & $\begin{array}{l}\text { Calculated } \\
\text { DP }\end{array}$ & $\begin{array}{l}\text { Theoretical } \\
\% \mathrm{~W}_{\mathrm{h}}[\%]\end{array}$ & $\begin{array}{l}\text { Calculated } \\
\% \mathrm{~W}_{\mathrm{h}}[\%]\end{array}$ & $\begin{array}{l}\text { Theoretical } \\
\text { calculated } \\
\text { molar ratio } \\
\text { PEP/PED/DED }\end{array}$ & $\begin{array}{l}\text { NMR calculated } \\
\text { molar ratio } \\
\mathrm{PEP} / \mathrm{PED} / \mathrm{DED}\end{array}$ \\
\hline $\begin{array}{l}\text { PET-DLA } \\
40 \%\end{array}$ & 2.07 & 2.00 & 40 & 39.0 & $0.46 / 0.44 / 0.1$ & $0.45 / 0.44 / 0.11$ \\
\hline $0.05 \% \mathrm{CB}$ & 2.07 & 1.95 & 40 & 39.0 & $0.46 / 0.44 / 0.1$ & $0.45 / 0.44 / 0.11$ \\
\hline $0.1 \% \mathrm{CB}$ & 2.07 & 1.95 & 40 & 39.0 & $0.46 / 0.44 / 0.1$ & $0.45 / 0.44 / 0.11$ \\
\hline $0.25 \% \mathrm{CB}$ & 2.07 & 1.90 & 40 & 38.0 & $0.46 / 0.44 / 0.1$ & $0.43 / 0.45 / 0.12$ \\
\hline $0.5 \% \mathrm{CB}$ & 2.07 & 1.90 & 40 & 38.0 & $0.46 / 0.44 / 0.1$ & $0.43 / 0.45 / 0.12$ \\
\hline $1 \% \mathrm{CB}$ & 2.07 & 1.90 & 40 & 38.0 & $0.46 / 0.44 / 0.1$ & $0.43 / 0.45 / 0.12$ \\
\hline $0.05 \%$ Gra & 2.07 & 1.90 & 40 & 38.0 & $0.46 / 0.44 / 0.1$ & $0.43 / 0.45 / 0.12$ \\
\hline $0.1 \%$ Gra & 2.07 & 1.95 & 40 & 39.0 & $0.46 / 0.44 / 0.1$ & $0.45 / 0.44 / 0.11$ \\
\hline $0.25 \% \mathrm{Gra}$ & 2.07 & 1.90 & 40 & 38.0 & $0.46 / 0.44 / 0.1$ & $0.43 / 0.45 / 0.12$ \\
\hline $0.5 \%$ Gra & 2.07 & 1.90 & 40 & 38.0 & $0.46 / 0.44 / 0.1$ & $0.43 / 0.45 / 0.12$ \\
\hline $1 \%$ Gra & 2.07 & 1.90 & 40 & 38.0 & $0.46 / 0.44 / 0.1$ & $0.43 / 0.45 / 0.12$ \\
\hline $0.05 \% \mathrm{CNT}$ & 2.07 & 2.0 & 40 & 39.0 & $0.46 / 0.44 / 0.1$ & $0.45 / 0.44 / 0.11$ \\
\hline $0.1 \% \mathrm{CNT}$ & 2.07 & 1.9 & 40 & 38.0 & $0.46 / 0.44 / 0.1$ & $0.43 / 0.45 / 0.12$ \\
\hline $0.25 \% \mathrm{CNT}$ & 2.07 & 2.0 & 40 & 39.5 & $0.46 / 0.44 / 0.1$ & $0.45 / 0.44 / 0.11$ \\
\hline $0.5 \% \mathrm{CNT}$ & 2.07 & 2.0 & 40 & 39.5 & $0.46 / 0.44 / 0.1$ & $0.45 / 0.44 / 0.11$ \\
\hline $\begin{array}{l}\text { PET-DLA } \\
60 \%\end{array}$ & 4.65 & 4.75 & 60 & 60.5 & $0.67 / 0.3 / 0.03$ & $0.68 / 0.29 / 0.03$ \\
\hline $0.05 \% \mathrm{CB}$ & 4.65 & 4.60 & 60 & 59.5 & $0.67 / 0.3 / 0.03$ & $0.67 / 0.30 / 0.03$ \\
\hline $0.1 \% \mathrm{CB}$ & 4.65 & 4.35 & 60 & 58.0 & $0.67 / 0.3 / 0.03$ & $0.66 / 0.30 / 0.04$ \\
\hline $0.25 \% \mathrm{CB}$ & 4.65 & 4.55 & 60 & 59.5 & $0.67 / 0.3 / 0.03$ & $0.67 / 0.30 / 0.03$ \\
\hline $0.5 \% \mathrm{CB}$ & 4.65 & 4.55 & 60 & 59.5 & $0.67 / 0.3 / 0.03$ & $0.67 / 0.30 / 0.03$ \\
\hline $1 \% \mathrm{CB}$ & 4.65 & 4.55 & 60 & 59.5 & $0.67 / 0.3 / 0.03$ & $0.67 / 0.30 / 0.03$ \\
\hline $0.05 \%$ Gra & 4.65 & 4.17 & 60 & 57.0 & $0.67 / 0.3 / 0.03$ & $0.65 / 0.31 / 0.04$ \\
\hline $0.1 \%$ Gra & 4.65 & 4.55 & 60 & 59.5 & $0.67 / 0.3 / 0.03$ & $0.67 / 0.30 / 0.03$ \\
\hline $0.25 \%$ Gra & 4.65 & 4.34 & 60 & 58.5 & $0.67 / 0.3 / 0.03$ & $0.66 / 0.30 / 0.04$ \\
\hline $0.5 \% \mathrm{Gra}$ & 4.65 & 4.75 & 60 & 60.5 & $0.67 / 0.3 / 0.03$ & $0.68 / 0.29 / 0.03$ \\
\hline $1 \%$ Gra & 4.65 & 4.52 & 60 & 59.5 & $0.67 / 0.3 / 0.03$ & $0.67 / 0.30 / 0.03$ \\
\hline $0.05 \% \mathrm{CNT}$ & 4.65 & 4.35 & 60 & 58.5 & $0.67 / 0.3 / 0.03$ & $0.66 / 0.30 / 0.04$ \\
\hline $0.1 \% \mathrm{CNT}$ & 4.65 & 4.35 & 60 & 58.5 & $0.67 / 0.3 / 0.03$ & $0.66 / 0.30 / 0.04$ \\
\hline $0.25 \% \mathrm{CNT}$ & 4.65 & 4.15 & 60 & 57.0 & $0.67 / 0.3 / 0.03$ & $0.65 / 0.31 / 0.04$ \\
\hline $0.5 \% \mathrm{CNT}$ & 4.65 & 4.75 & 60 & 60.5 & $0.67 / 0.3 / 0.03$ & $0.68 / 0.29 / 0.03$ \\
\hline
\end{tabular}


The obtained results fit well with the theoretical values for each copolymer nanocomposite. Importantly, the incorporation of nanofillers did not affect the DP or weight percentage of segments; the small differences between calculated values and theoretical ones can be attributed to slightly different synthesis conditions and/or measurement error.

\subsection{Thermal analysis}

PET-DLA copolymer exhibit two major transitions (Tables 3 and 4) ascribed to microphase separated structure characteristic for thermoplastic elastomers: low temperature glass transition $\left(\mathrm{T}_{\mathrm{g} 1}\right)$ of soft segments and high melting point $\left(\mathrm{T}_{\mathrm{m} 2}\right)$ of hard, semicrystalline segments. Additionally, as can be seen from Table 3, neat PET-DLA 40\% exhibits a cold crystallization $\left(\mathrm{T}_{\mathrm{cc} 2}\right)$. However, none of the obtained nanocomposites exhibit cold crystallization peaks, because the presence of nanofillers favours the formation of crystalline regions during the cooling stage.

For all of the PET-DLA 40\% nanocomposites, the glass transition temperatures are lower as compared to neat PET-DLA $40 \%$ polymer (Table 3), from $-19^{\circ} \mathrm{C}$ to about $-23{ }^{\circ} \mathrm{C}$. Although this change may not be significant, materials containing $60 \mathrm{wt} \%$ of PET hard segments (Table 4) showed a very different dependence-their $\mathrm{T}_{\mathrm{g} 1}$ did not changed as compared to the neat PET-DLA $60 \%$ copolymer $\left(\mathrm{T}_{\mathrm{g} 1}\right.$ was approx. $-4{ }^{\circ} \mathrm{C}$ to $\left.-5^{\circ} \mathrm{C}\right)$. The slight shift towards lower temperatures for PET-DLA $40 \%$ nanocomposites can be ascribed to a plastifying effect reducing interactions between macrochains and, thus, lowering the glass transition temperature.

The aspect ratio of the nanofiller did not significantly change the melting temperature, $\mathrm{T}_{\mathrm{m} 2}$ of all nanocomposites from PET-DLA 40\% series (Table 3), however a slightly increased $\mathrm{T}_{\mathrm{m} 2}$ and melting enthalpy can be observed for materials containing nanofillers with high aspect ratio (graphene and CNTs). In contrast, nanocomposites from the PET-DLA 60\% 
series (Table 4), exhibit decreased melting temperature, for nano-fillers with low aspect ratio, especially for $\mathrm{CB}$, but also for graphene. Therefore, melting behavior of carbon nanofillerbased nanocomposites can be controlled not only by nanofiller shape, but also by polymer matrix microstructure (PET-DLA 40\% copolymer is more amorphous than PET-DLA 60\%).

During the cooling stage, all nanocomposites exhibit crystallization that is in the same temperature range, approx. $95-103{ }^{\circ} \mathrm{C}$. No significant differences in $\mathrm{T}_{\mathrm{c} 2}$ can be seen within each series with different content of various nanofillers. Thus, all nanofillers nucleate PETDLA $40 \%$ crystallization, independently of aspect ratio, and therefore strongly affect polymer thermal behavior. In contrast, significant changes can be seen for nanocomposites from the PET-DLA 60\% series (Table 4); the crystallization temperature, $\mathrm{T}_{\mathrm{c} 2}$ is increased by $30{ }^{\circ} \mathrm{C}$ as compared to the neat polymer and the highest increase in $\mathrm{T}_{\mathrm{c} 2}$ was measured for nanocomposites containing nanofiller with the highest aspect ratio (CNTs). This is an indication of a strong nucleating effect of carbon nanofillers on crystallization of the polymer matrix.

Table 3. Thermal analysis of PET-DLA 40 nanocomposites series

\begin{tabular}{|l|l|l|l|l|l|l|l|}
\hline \multirow{2}{*}{ Sample } & \multicolumn{2}{|c|}{ Soft segments } & \multicolumn{7}{c|}{ Hard segments } \\
\cline { 2 - 8 } & $\begin{array}{c}\mathrm{T}_{\mathrm{g} 1} \\
\left({ }^{\circ} \mathrm{C}\right)\end{array}$ & $\begin{array}{c}\Delta \mathrm{C}_{\mathrm{p}} \\
\mathrm{J} /\left(\mathrm{g} *^{\circ} \mathrm{C}\right)\end{array}$ & $\begin{array}{c}\mathrm{T}_{\mathrm{cc} 2} \\
\left({ }^{\circ} \mathrm{C}\right)\end{array}$ & $\begin{array}{r}\mathrm{T}_{\mathrm{m} 2} \\
\left({ }^{\circ} \mathrm{C}\right)\end{array}$ & $\begin{array}{c}\Delta \mathrm{H}_{\mathrm{m} 2} \\
\mathrm{~J} / \mathrm{g}\end{array}$ & $\begin{array}{c}\mathrm{T}_{\mathrm{c} 2} \\
\left({ }^{\circ} \mathrm{C}\right)\end{array}$ & $\begin{array}{c}\mathrm{W}_{\mathrm{c}, \mathrm{h}} \\
(\%)\end{array}$ \\
\hline PET-DLA 40 & -19.1 & 0.51 & 87.2 & 166.2 & 11.3 & - & 8.0 \\
\hline $0.05 \% \mathrm{CB}$ & -22.3 & 0.39 & - & 163.2 & 12.11 & 95.2 & 8.5 \\
$0.1 \% \mathrm{CB}$ & -22.5 & 0.46 & - & 164.1 & 12.31 & 96.1 & 9.0 \\
$0.25 \% \mathrm{CB}$ & -23.1 & 0.46 & - & 164.3 & 10.84 & 100 & 8.0 \\
$0.5 \% \mathrm{CB}$ & -23.4 & 0.44 & - & 164.3 & 11.12 & 99.3 & 8.0 \\
$1 \% \mathrm{CB}$ & -23.3 & 0.43 & - & 166 & 11.35 & 105 & 8.0 \\
\hline $0.05 \%$ Gra & -23.1 & 0.39 & - & 167.2 & 21.03 & 95.3 & 12.0 \\
$0.1 \%$ Gra & -23.1 & 0.38 & - & 167.4 & 20.19 & 95.6 & 12.5 \\
$0.25 \%$ Gra & -23.4 & 0.36 & - & 167.4 & 20.02 & 104.3 & 13.0 \\
$0.5 \%$ Gra & -23.3 & 0.37 & - & 165.6 & 18.07 & 101.2 & 13.0 \\
$1 \%$ Gra & -23.1 & 0.35 & - & 167.2 & 17.90 & 108.4 & 12.0 \\
\hline
\end{tabular}




\begin{tabular}{|l|l|l|l|l|l|l|l|}
\hline $0.05 \% \mathrm{CNT}$ & -23.2 & 0.42 & - & 166.2 & 13.31 & 104.2 & 9.5 \\
$0.1 \% \mathrm{CNT}$ & -22.6 & 0.41 & - & 165.6 & 13.20 & 100.8 & 9.5 \\
$0.25 \% \mathrm{CNT}$ & -22.5 & 0.42 & - & 168.3 & 12.64 & 105.3 & 9.0 \\
$0.5 \% \mathrm{CNT}$ & -22.6 & 0.41 & - & 169.2 & 14.49 & 104.5 & 10.5 \\
\hline
\end{tabular}

$T_{g l}$-glass transition of the soft segments, $\Delta C_{p}$ - change of the heat capacity at glass transition; $T_{g 2}$, $T_{m 2}, T_{c 2^{-}}$glass transition, melting, and crystallization temperatures, respectively, of the hard segments; $T_{c c 2}$ - cold crystallization; $\Delta H_{m 2}$ - melting enthalpy of the hard segments; $W_{c, h}$-mass content of PET crystallites in the polymer.

Table 4. Thermal analysis of PET-DLA 60 nanocomposites series

\begin{tabular}{|c|c|c|c|c|c|c|c|}
\hline \multirow[b]{2}{*}{ Sample } & \multicolumn{2}{|c|}{ Soft segments } & \multicolumn{5}{|c|}{ Hard segments } \\
\hline & $\begin{array}{l}\mathrm{T}_{\mathrm{g} 1} \\
\left({ }^{\circ} \mathrm{C}\right)\end{array}$ & $\begin{array}{c}\mathrm{DC}_{\mathrm{p}} \\
\mathrm{J} / \mathrm{g} /{ }^{\circ} \mathrm{C}\end{array}$ & $\begin{array}{l}\mathrm{T}_{\mathrm{cc} 2} \\
\left({ }^{\circ} \mathrm{C}\right)\end{array}$ & $\begin{array}{l}\mathrm{T}_{\mathrm{m} 2} \\
\left({ }^{\circ} \mathrm{C}\right)\end{array}$ & $\begin{array}{c}\mathrm{DH}_{\mathrm{m} 2} \\
\mathrm{~J} / \mathrm{g}\end{array}$ & $\begin{array}{l}\mathrm{T}_{\mathrm{c} 2} \\
\left({ }^{\circ} \mathrm{C}\right)\end{array}$ & $\begin{array}{l}\mathrm{W}_{\mathrm{c}, \mathrm{h}} \\
(\%)\end{array}$ \\
\hline PET-DLA 60 & -5.4 & 0.35 & - & 216.3 & 20.40 & 120.3 & 15.0 \\
\hline $0.05 \% \mathrm{CB}$ & -4.2 & 0.40 & - & 209.4 & 17.13 & 155.3 & 12.0 \\
\hline $0.1 \% \mathrm{CB}$ & -4.2 & 0.38 & - & 209.6 & 16.03 & 155.6 & 12.0 \\
\hline $0.25 \% \mathrm{CB}$ & -5.3 & 0.38 & - & 210.0 & 16.13 & 157.4 & 12.0 \\
\hline $0.5 \% \mathrm{CB}$ & -3.7 & 0.43 & - & 211.4 & 17.36 & 160.1 & 12.0 \\
\hline $1 \% \mathrm{CB}$ & -5.1 & 0.38 & - & 210.7 & 15.25 & 158.8 & 11.0 \\
\hline $0.05 \%$ Gra & -4.8 & 0.37 & - & 208.6 & 17.29 & 150.1 & 12.0 \\
\hline $0.1 \%$ Gra & -4.7 & 0.37 & - & 208.7 & 17.78 & 151.7 & 13.0 \\
\hline $0.25 \%$ Gra & -4.6 & 0.24 & - & 214.3 & 15.85 & 167.3 & 11.0 \\
\hline $0.5 \%$ Gra & -3.6 & 0.28 & - & 213.5 & 17.08 & 165.7 & 12.0 \\
\hline $1 \%$ Gra & -4.5 & 0.26 & - & 213.4 & 15.11 & 166.2 & 11.0 \\
\hline $0.05 \% \mathrm{CNT}$ & -4.2 & 0.36 & - & 216.3 & 22.52 & 169.7 & 16.0 \\
\hline $0.1 \% \mathrm{CNT}$ & -4.4 & 0.34 & - & 213.4 & 18.06 & 160.6 & 13.0 \\
\hline $0.25 \% \mathrm{CNT}$ & -4.5 & 0.35 & - & 214.2 & 20.09 & 162.4 & 15.0 \\
\hline $0.5 \%$ CNT & -0.9 & 0.31 & - & 218.3 & 22.57 & 168.4 & 16.0 \\
\hline
\end{tabular}

$T_{g l}$-glass transition of the soft segments, $\Delta C_{p}$ - change of the heat capacity at glass transition; $T_{g 2}$, $T_{m 2}, T_{c 2^{-}}$glass transition, melting, and crystallization temperatures, respectively, of the hard segments; $T_{c c 2}$ - cold crystallization; $\Delta H_{m 2}$ - melting enthalpy of the hard segments; $W_{c, h}$-mass content of PET crystallites in the polymer.

\subsection{Mechanical properties}

The mechanical properties of neat PET-DLA copolymers containing 40 and $60 \mathrm{wt} \%$ of hard segments, as well as the obtained nanocomposites are presented in Figures 5 and 6 , respectively. 
a)
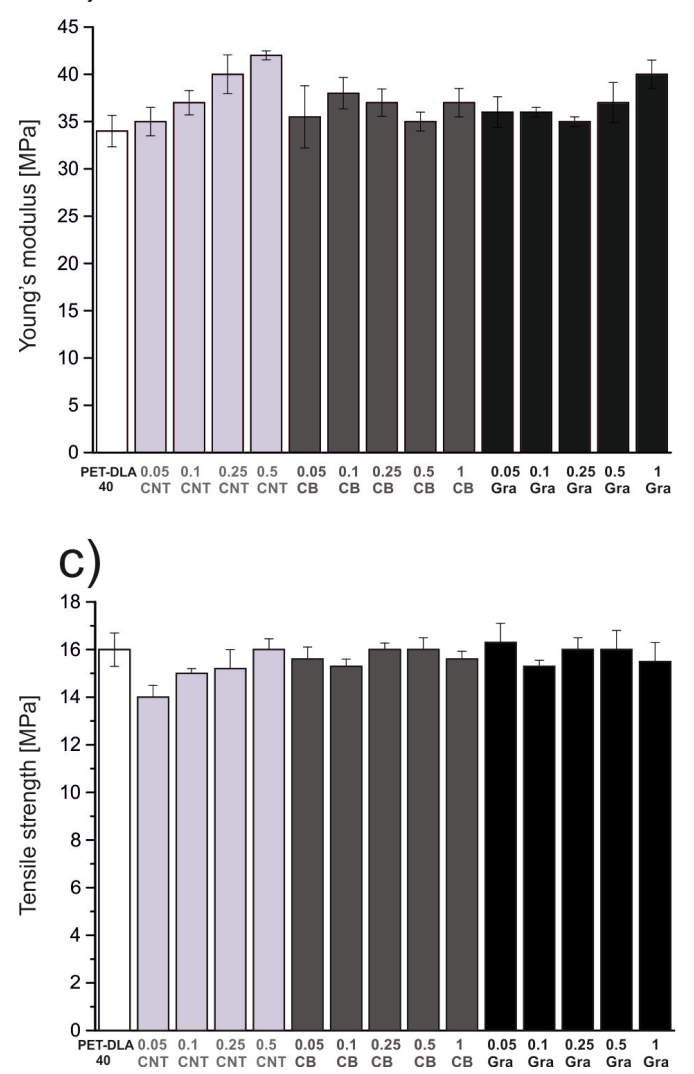

b)
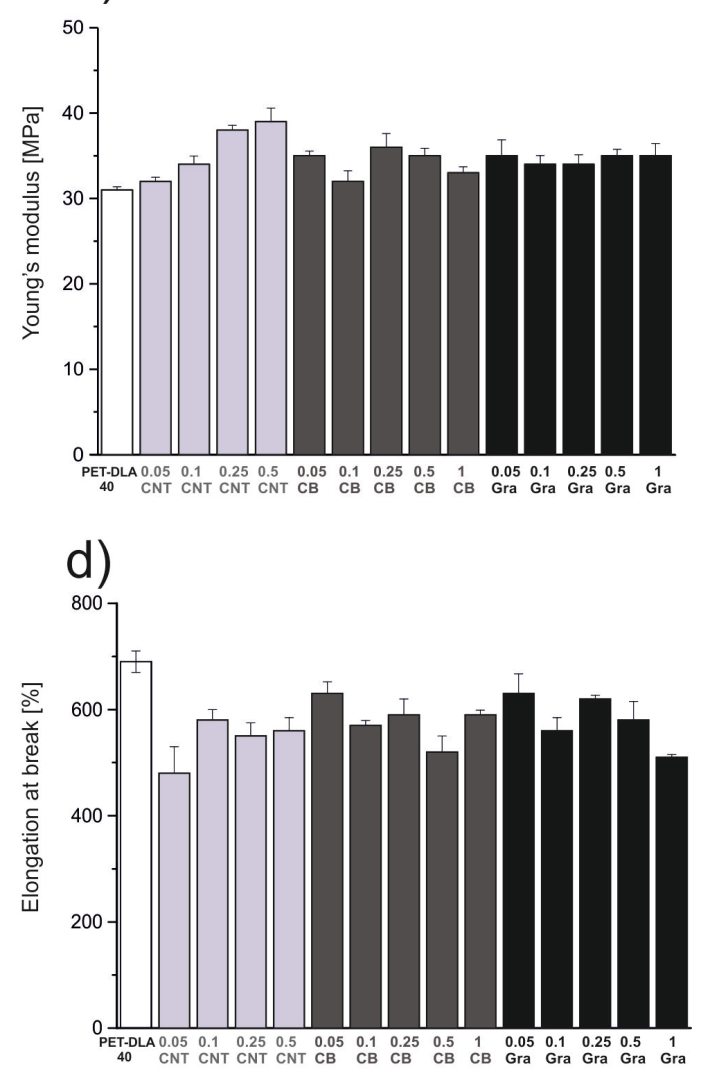

Figure 5. Mechanical properties of nanocomposites based on PET-DLA $40 \mathrm{wt} \%$ polymer matrix. a) Young's modulus at $24^{\circ} \mathrm{C}$; b) Young's modulus at $37^{\circ} \mathrm{C}$; c) tensile strength at $24^{\circ} \mathrm{C}$; d) elongation at break at $24^{\circ} \mathrm{C}$.

All PET-DLA $40 \mathrm{wt} \%$ nanocomposites exhibit increased values of Young's modulus, compared to neat PET-DLA $40 \mathrm{wt} \%$, especially at $37^{\circ} \mathrm{C}$ (Figure 5b). For the PET-DLA 40 wt $\%$ matrix, the addition of CNT nanofiller resulted in the largest increase in Young's modulus at $24^{\circ} \mathrm{C}$ and $37^{\circ} \mathrm{C}$, up to $30 \%$ (for material containing $0.5 \mathrm{wt} \%$ of $\mathrm{CNT}$ ). All the other nanocomposites showed an increase in Young's modulus values at $24^{\circ} \mathrm{C}$ and $37^{\circ} \mathrm{C}$ up to approx. $15 \%$, in comparison with neat polymer. Due to the technical limitations of our environmental chamber, it was impossible to reach tensile strength and elongation at break values (up to $600 \%$ ) at $37^{\circ} \mathrm{C}$, therefore we are not able to compare those values. However, at $24^{\circ} \mathrm{C}$, the tensile strength values of all PET-DLA $40 \mathrm{wt} \%$ nanocomposites were comparable, 
approx. $15 \mathrm{MPa}$ (Figure 5c) and elongation at break values were lower than neat PET-DLA $40 \mathrm{wt} \%$, but no trend was observed (Figure 6c). The change in tensile strength is very marginal, indicating the poor interaction of the nanofillers with the PET-DLA polymer matrix. However, this is to be expected, since we used unmodified carbon nanofillers and, as FTIR and ${ }^{1} \mathrm{H}$ NMR spectroscopy indicated, there is no significant chemical interaction between nanofiller and polymer matrix.

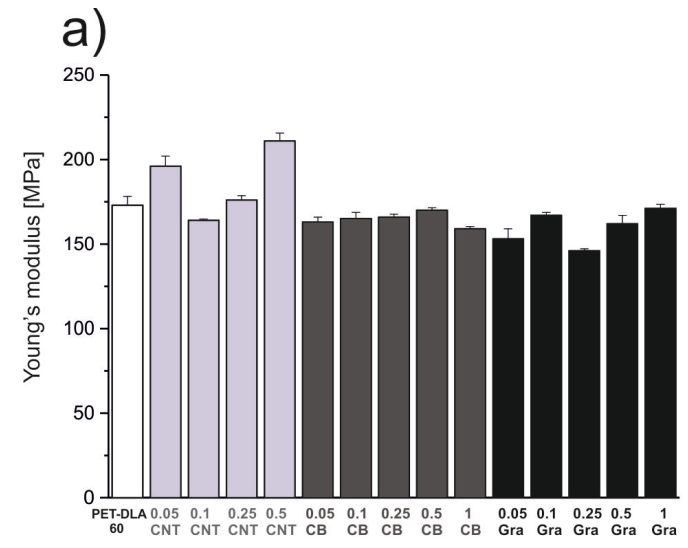

c)

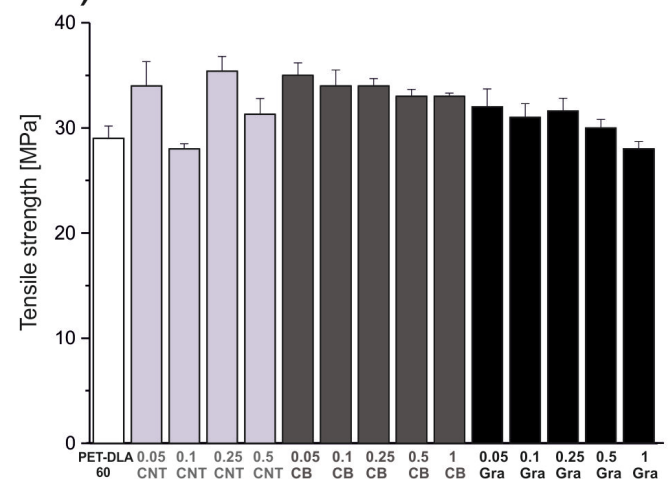

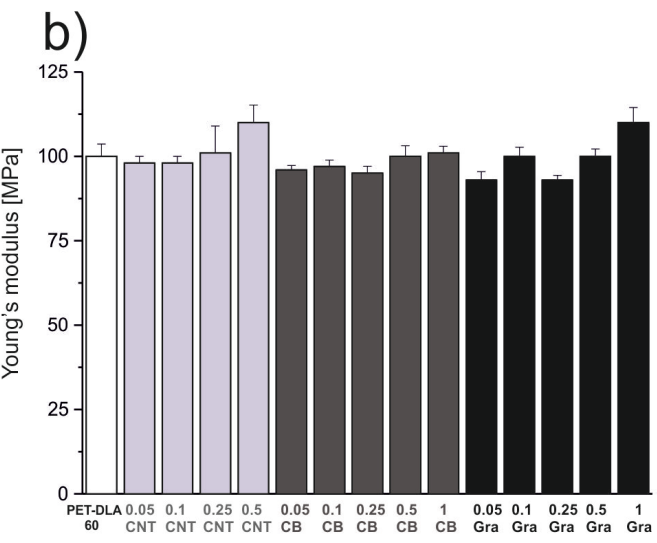

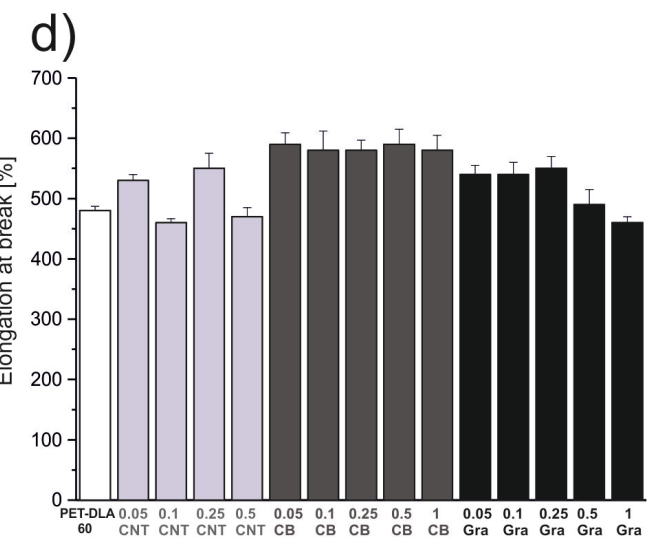

Figure 6. Mechanical properties of nanocomposites based on PET-DLA $60 \mathrm{wt} \%$ polymer matrix. a) Young's modulus at $24^{\circ} \mathrm{C}$; b) Young's modulus at $37^{\circ} \mathrm{C}$; c) tensile strength at $24^{\circ} \mathrm{C}$; d) elongation at break in $24^{\circ} \mathrm{C}$.

For the case of PET-DLA $60 \mathrm{wt} \%$ matrix, the addition of $\mathrm{CNT}$ as nanofillers also yielded the largest increase in Young's modulus, up to approx. 30\%; however, the measured values were not linearly dependent on concentration at $24^{\circ} \mathrm{C}$. For materials containing $\mathrm{CB}$ 
and graphene nanofillers, Young's modulus values were comparable, or slightly lower, to neat copolymer matrix at $24^{\circ} \mathrm{C}$ and at comparable level at $37^{\circ} \mathrm{C}$, with the exception of $1.0 \%$ graphene, which is $15 \%$ higher. Interestingly, tensile strength for all of obtained nanocomposites is higher than for neat material (Figure 6c), except of materials containing $0.1 \%$ CNT.

Since our materials are multiblock copolymers, containing hard and soft segments, their useful application temperature range is limited by the glass transition temperature $\left(\mathrm{T}_{\mathrm{g}}\right)$ of soft segments and the $T_{g}$ of hard segments [22]. For PET-DLA $40 \mathrm{wt} \%$ the $T_{g}$ is approx. $-18^{\circ} \mathrm{C}$ and PET-DLA $60 \mathrm{wt} \%$ has $\mathrm{T}_{\mathrm{g}}$ of approx. $-5^{\circ} \mathrm{C}$ [7]. Thus, below the $\mathrm{T}_{\mathrm{g}}$ of the DLA soft segments, the materials are in a glassy state with no elastomeric properties, however with high tensile strength. Above the $T_{g}$ of the soft segments, on the other hand, the tensile strength of the materials is much lower. The upper temperature limit is related to the softening of hard segments and it depends on hard segments length, domain size, and phase separation. Importantly, our results at $37^{\circ} \mathrm{C}$ indicate that the mechanical properties are stable, so we assume that the materials will maintain their mechanical properties if used as a biomaterial within the human body.

\subsection{High resolution scanning electron microscopy (HR-SEM)}

High resolution scanning electron microscopy (HR-SEM) was used to examine the dispersion of carbon nanofillers within the polymer matrices and to investigate the morphology of obtained nanocomposites. Neat PET-DLA $40 \mathrm{wt} \%$ and PET-DLA $60 \mathrm{wt} \%$ polymers are shown in Figure 8. 

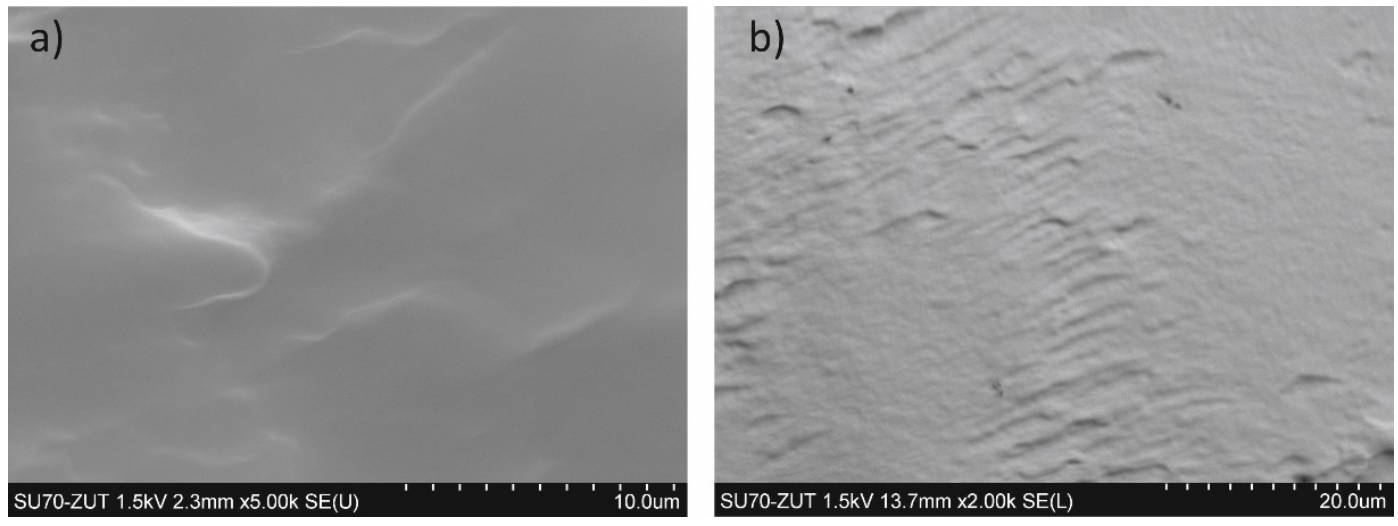

Figure 8. HRSEM micrographs of neat a) PET-DLA $40 \mathrm{wt} \%$ and b) PET-DLA $60 \mathrm{wt} \%$.

In Figure 9 and 10, we present HR-SEM micrographs of PET-DLA $40 \mathrm{wt} \%$ and PETDLA $60 \mathrm{wt} \%$ nanocomposites, respectively. Overall, the SEM images indicate that we obtained very good dispersion of each carbon nanofillers in both the PET-DLA $40 \mathrm{wt} \%$ matrix and the PET-DLA $60 \mathrm{wt} \%$ matrix. The micrographs clearly show the difference between amorphous carbon black and the crystalline particles of both carbon nanotubes and graphene. 

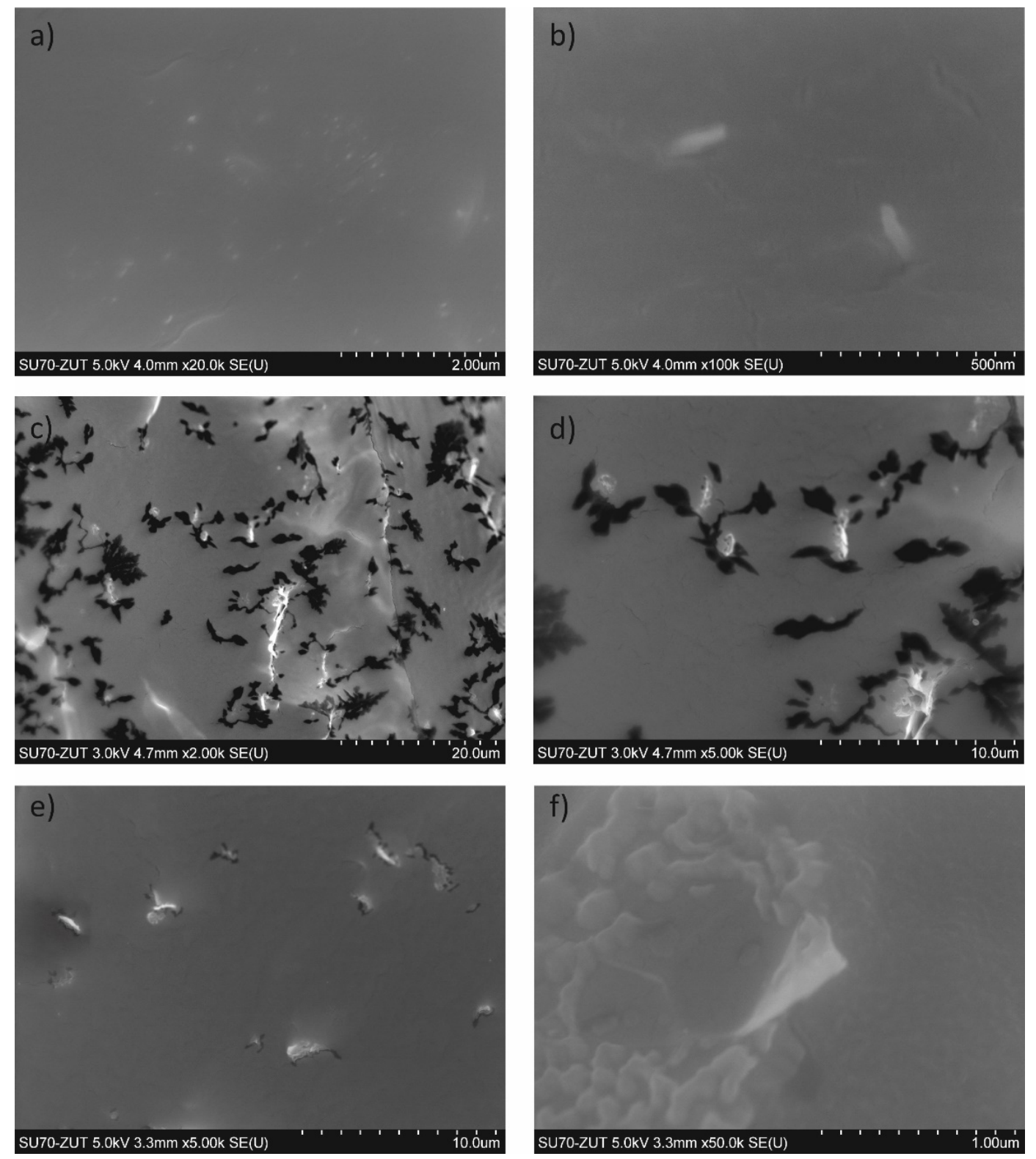

Figure 9. HR-SEM micrographs of PET-DLA $40 \mathrm{wt} \%$ containing a,b) PET-DLA $40 \mathrm{wt} \%$ + $1 \% \mathrm{CB}, \mathrm{c}, \mathrm{d})$ PET-DLA $40 \mathrm{wt} \%+0.5 \%$ CNT and e,f) PET-DLA $40 \mathrm{wt} \%+1 \%$ graphene

(right panel shows sample surface at higher magnification). 

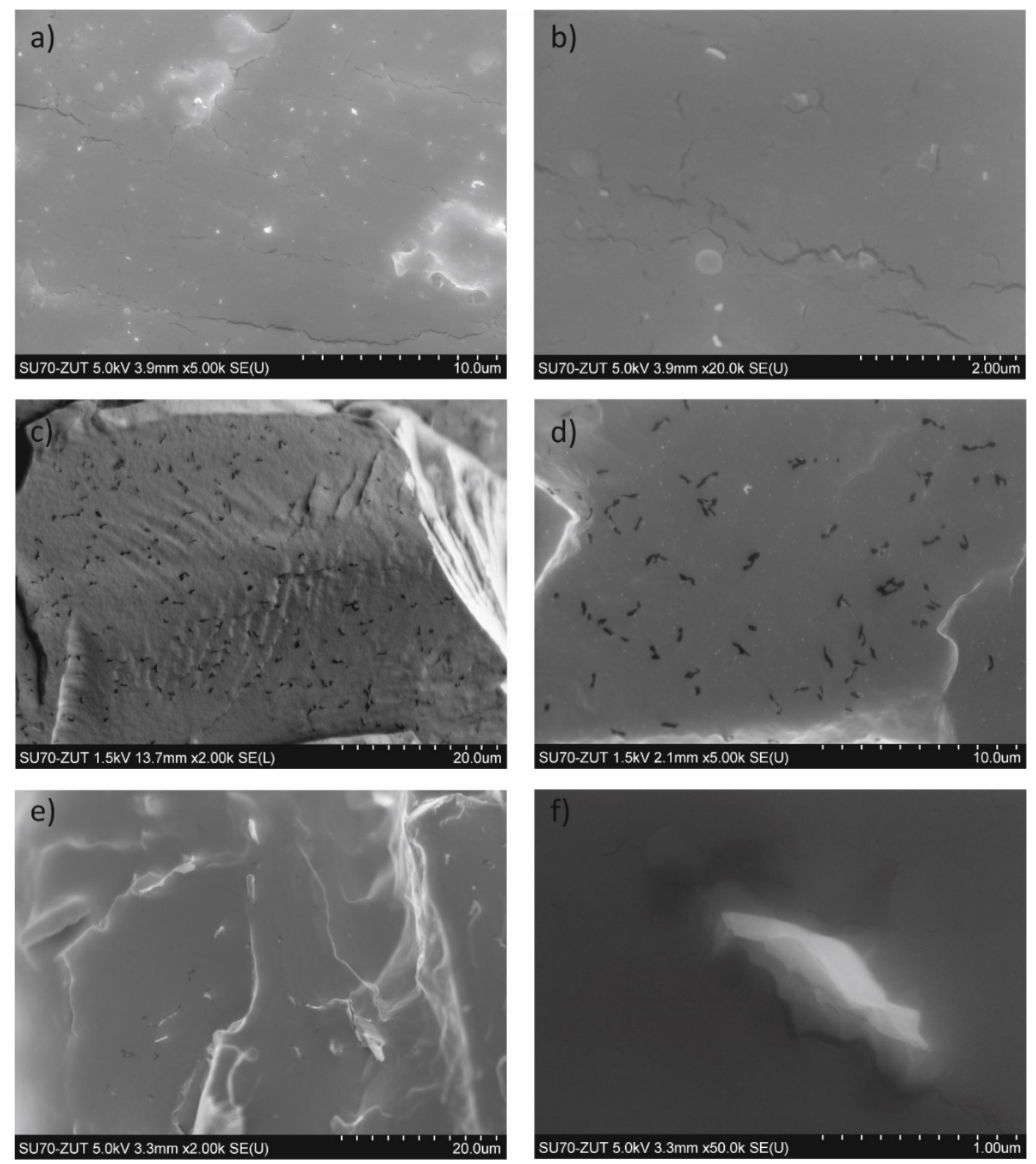

Figure 10. HR-SEM micrographs of PET-DLA $60 \mathrm{wt} \%$ containing a,b) PET-DLA $60 \mathrm{wt} \%+$ $1 \% \mathrm{CB}, \mathrm{c}, \mathrm{d})$ PET-DLA $60 \mathrm{wt} \%+0.5 \%$ CNT and e,f) PET-DLA $60 \mathrm{wt} \%+1 \%$ graphene

(right panel shows sample surface at higher magnification).

\subsection{Water contact angle}

The wetting properties of polymeric materials are very important for applications in biomedical devices or implants. For example, in general hydrophilic surfaces exhibit reduced protein adsorption [23], potentially improving biocompatibility, but tend to foster bacterial 
cell attachment [24]. To study the surface wetting character of our materials, water contact angle measurements of neat polymers and nanocomposites containing maximum amount of each nanofiller were performed and the results are presented in Table 5.

Table 5. Water contact angle and surface roughness of nanocomposites with highest content of carbon nano-fillers.

\begin{tabular}{|l|l|l|}
\hline Material & Contact angle ${ }^{\circ}{ }^{\circ}$ & Surface roughness $\mathrm{R}_{\mathrm{q}}[\mu \mathrm{m}]$ \\
\hline PET-DLA 40 & $90+/-2$ & 0.095 \\
\hline PET-DLA $40+0.5 \% \mathrm{CNT}$ & $87+/-3$ & 0.137 \\
\hline PET-DLA $40+1 \% \mathrm{CB}$ & $91+/-2$ & 0.218 \\
\hline PET-DLA $40+1 \%$ graphene & $90+/-1$ & 0.293 \\
\hline PET-DLA 60 & $87+/-3$ & 0.817 \\
\hline PET-DLA $60+0.5 \%$ CNT & $85+/-2$ & 0.826 \\
\hline PET-DLA $60+1 \%$ CB & $87+/-2$ & 0.762 \\
\hline PET-DLA $60+1 \%$ graphene & $86+/-4$ & 0.506 \\
\hline
\end{tabular}

Both neat PET-DLA polymers exhibited water contact angle values of approximately $90^{\circ}$. Modification of either matrix with carbon nanofillers did not have a strong effect on the water contact angle. In Table 2, we also present the surface roughness measurements (root mean square roughness, $\mathrm{R}_{\mathrm{q}}$ ) as determined using laser scanning microscopy. According to the Wenzel model, surface roughness enhances the effect of surface chemistry on contact angle [25], according to the equation (4):

$$
\cos \theta_{z}=r \cdot \cos \theta_{Y}
$$


where: $\theta_{\mathrm{z}}$ is the measured contact angle, $\theta_{\mathrm{y}}$ is the Young contact angle, of ideal, flat surface, and $\mathrm{r}$ is the roughness ratio between the actual surface area and the projected, flat area.

And so, because $\mathrm{r}>1,\left|\cos \theta_{\mathrm{z}}\right|>\left|\cos \theta_{\mathrm{y}}\right|$ and thus, with increasing roughness hydrophobic materials become more hydrophobic, while hydrophilic materials become more hydrophilic. However, as shown in Table 5, both neat copolymer matrices, as well as all nanocomposites exhibited water contact angles near $90^{\circ}$, so $\cos \theta_{\mathrm{z}} \approx 0$. Therefore, $\cos \theta_{\mathrm{y}}$ must also be close to 0 . This explains the lack of significant changes in the contact angle despite the differences in roughness of the surface.

\subsection{Bacterial adhesion}

Figure 11 presents the results of bacterial adhesion studies on PET-DLA 40 and PETDLA 60 nanocomposites containing the highest amounts of each carbon nanofiller. For the PET-DLA 40 materials, only the inclusion of graphene nanofiller resulted in statistically significant increase in Gram-negative E. coli adhesion, as compared to neat PET-DLA 40, as well as PET-DLA 40 containing CNT nanofiller ( $\mathrm{p}=0.014$ and $\mathrm{p}=0.003$, respectively). For Gram-positive $S$. epidermidis, adhesion was approximately 10 times greater than $E$. coli, but a similar trend was observed, with highest adhesion on copolymer containing graphene nanofiller ( $\mathrm{p}=0.001$ vs. PET-DLA 40, $\mathrm{p}=0.013$ vs PET-DLA 40+CNT), however inclusion of carbon black also resulted in a statistically significant increase in adhesion as compared to neat copolymer $(\mathrm{p}=0.008)$. 

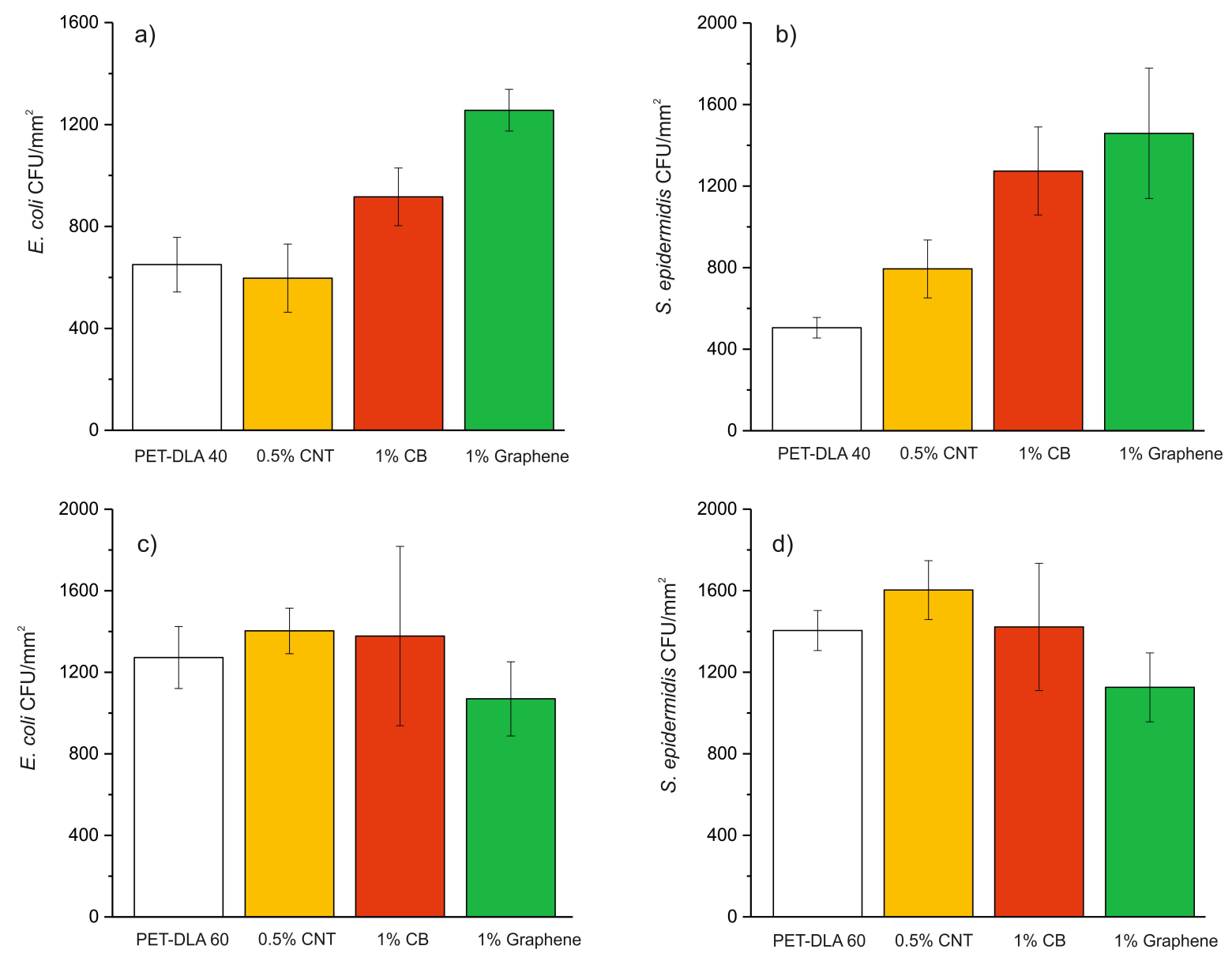

Figure 11. Bacterial adhesion of PET-DLA $40(\mathrm{a}, \mathrm{b})$ and PET-DLA 60 (c,d) nanocomposites containing the highest amounts of each carbon nanofiller.

For the PET-DLA 60 materials, no significant differences were observed in Gramnegative E. coli adhesion. For Gram-positive $S$. epidermidis, adhesion was again approximately 10 times greater than E. coli, as was observed for the PET-DLA 40 nanocomposites. Likewise, the observed trend S. epidermidis, adhesion was similar to that of E. coli, with the graphene nanocomposite being the lowest, however, it only significantly differed in adhesion from the CNT nanocomposites $(\mathrm{p}=0.033)$.

Bacterial adhesion to surfaces is a complex process, depending on characteristics of the microorganism, the surface, as well as environmental conditions [26,27]. In light of this, we interpret our results with caution. The most substantial observed difference, that between 
the two model organisms, is likely a function of differing surface free energy (SFE) of the organisms, due to their differing cell wall composition; E. coli has a greater (SFE) than $S$. epidermidis and exhibits markedly reduced adhesion to hydrophobic surfaces [27]. However, the differences between the nanocomposites may be the result of differences in surface roughness, which has a positive, though non-linear effect on adhesion, particularly when the roughness is on the same scale as the size of the organism [26]. For the nanocomposites presented here, the differences in roughness of the PET-DLA 40 nanocomposite are in the range where a large effect would be predicted and the trend in adhesion follows the roughness measurements (Table 5). Meanwhile for the PET-DLA 60 nanocomposites, the surface roughness of all of the materials exceeds the radius of a microorganism and as a result the differences in roughness do not substantially influence adhesion.

\subsection{In vitro cytocompatibility}

Figure 12 shows graphs of L929 mouse fibroblast viability after 72 and 96 hours on PET-DLA 40 and PET-DLA 60 nanocomposites containing the highest amounts of each carbon nanofiller. The results are presented as percent of fibroblast viability on tissue culture polystyrene (TCPS). For all tested materials, the results indicate markedly less cell viability as compared to near-confluent cells on TCPS. However, it is important to note that these materials do not possess any charged function groups or biofunctionalization, which could facilitate cell adhesion and thus growth of this adherent cell line. For PET-DLA 40 and PETDLA 60, as well as their nanocomposites containing carbon black and graphene as nanofillers, the reduced viability is likely due to relatively poor cell adhesion, as additional 24 hours of culture results in an increase in viability, indicating growth and sustained viability. Importantly, we do not observe any significant decrease in viability for these two nanocomposites, as compared to the neat polymers. On the other hand, for materials 
containing CNT nanofillers, viability at both time points was minimal, indicating both poor adhesion and no growth - poor cytocompatibilty. Statistical analysis with ANOVA followed by Dunnet's post hoc analysis indicates that this reduced viability on material with CNT nanofillers is statistically significantly, as compared to corresponding neat copolymer $(\mathrm{p}=0.015$ for PET-DLA 40 and $\mathrm{p}=0.007$ for PET-DLA 60).
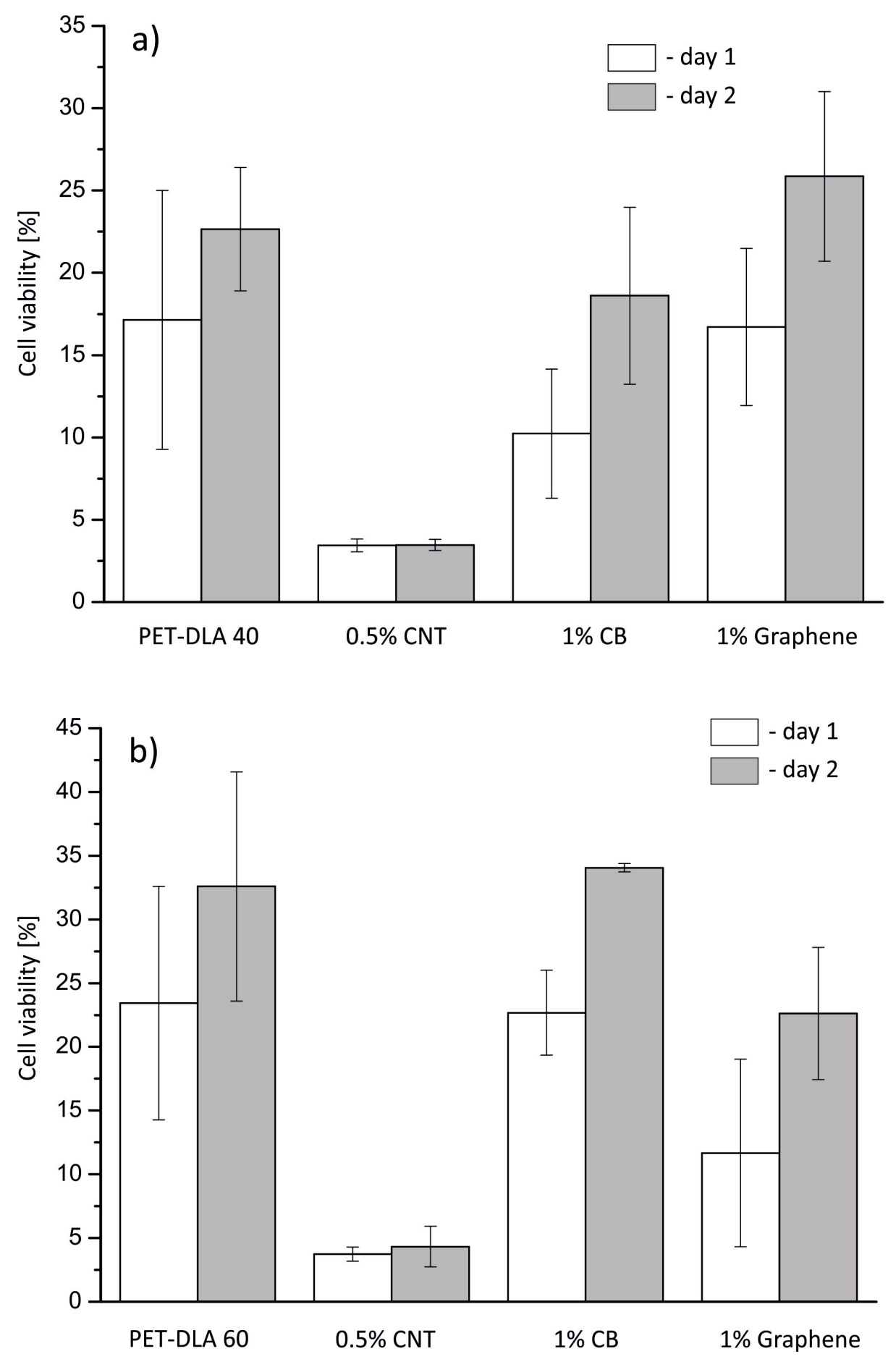
Figure 12. L929 fibroblast proliferation on nanocomposites surfaces a) PET-DLA 40, b) PET-DLA 60, normalized to TCPS (tissue culture polystyrene) (mean $\pm \mathrm{SD}, \mathrm{n}=4$ discs).

Additionally, there is a trend towards higher viability of L929 mouse fibroblast on materials containing $60 \mathrm{wt} \%$ of hard segments. This effect is probably related to greater adhesion of cells, which may be the result of a combination of increased roughness and stiffness of this matrix-stiffness of the polymer substrate can promote fibroblast adhesion $[29,30]$.

\section{Conclusions}

In the present work, we successfully synthesized segmented PET-DLA nanocomposites containing carbon nanofillers with different aspect ratios (dimensions): carbon black (0D), multiwalled carbon nanotubes (1D), and graphene (2D). The unmodified carbon nanofillers did not affect the chemical structure of obtained nanocomposites. HR-SEM imaging indicates very good dispersion in polymeric matrices. DSC data revealed that high aspect ratio nanofiller (1D multiwalled carbon nanotubes) strongly nucleates PET-DLA $60 \%$ crystallization and, therefore, strongly affects the thermal behavior of the nanocomposite. Mechanical properties of PET-DLA $40 \mathrm{wt} \%$ nanocomposites showed an increase in Young's modulus compared to neat materials, but no significant improvement in tensile strength and elongation at break were observed. Probably, the nanofiller-matrix interaction is too small to effectively carry the load from the polymer matrix to nanofillers. In the case of PET-DLA $60 \mathrm{wt} \%$ nanocomposites, the improvement of the Young's modulus was observed only for CNTcontaining nanocomposites, which is related to the high value of the aspect ratio, which influences the effective transfer of load between the nanofiller and the polymer matrix. Tensile strength of all nanocomposites was higher than for neat materials. In vitro cytocompatibility tests did not indicate any toxicity of carbon black and graphene as 
nanofillers. However, for nanocomposites containing carbon nanotubes, very low fibroblast viability was observed and no growth was observed, suggesting a cytostatic or cytotoxic effect.

\section{Acknowledgements}

This work received financial support from the National Centre for Research and Development (PBS1/A5/2/2012). The authors thank Dr. Karol Fijałkowski (Faculty of Biotechnology and Animal Husbandry, ZUT) for access to microplate reader and Monika Dymecka and Aleksandra Wcisłek for help with microbiological experiments.

\section{References}

[1] Kulshrestha A. S., Mahapatro A.: "Polymers for Biomedical Applications", American Chemical Society, San Francisco 2008, p. 535.

[2] Antic V.V, Govedarica M.N., Djonlagic J.: Polymer International 2004, 11, 1786. http://dx.doi.org/10.1002/pi.1582

[3] El Fray M., Słonecki J.: Macromolecular Materials and Engineering 1996, 1, 103. http://dx.doi.org/10.1002/apmc.1996.052340110

[4] Lepoittevin B., Roger P.: "Handbook of Engineering and Speciality Thermoplastics: Polyethers and Polyesters, Volume 3", (red. Sabu T., Visakh P.M.), Wiley-Scrivener, Chichester 2011, p.102.

[5] Piegat A., El Fray M.: Polimery 2007, 52, 885.

[6] El Fray M., Czugala M.: Polish Artificial Heart Program, WIREs Nanomedicine \& Nanobiotechnology, 2012,4, 322. http://dx.doi.org/10.1002/wnan.175 
[7] Staniszewski Z., Piegat A., Piątek-Hnat M., El Fray M.: The effect of catalyst and segmental composition on the crystallization of multiblock polyesters for biomedical applications, Polimery, 2014, 7-8, 592. http://dx.doi.org/ 10.14314/polimery.2014.592

[8] Koyama S., Haniu H., Osaka K., et al.: Small 2006, 12, 1406. http://dx.doi.org/10.1002/smll.200500416

[9] Choudhary V., Gupta A.: “Carbon Nanotubes - Polymer Nanocomposites”, (red. Siva Yellampalli), InTech, Rijeka 2011, p. 65.

[10] Potts J.R., Dreyer D.R., Bielawski C.W., et al.: Polymer 2011, 1, 5. http://dx.doi.org/10.1016/j.polymer.2010.11.042

[11] Sadrani S. A., Ramazani S.A.A., Khorshidiyeh S.E., et al.: Polymer Bulletin 2006, 4, 1085. http://dx.doi.org/10.1007/s00289-015-1536-8

[12] McNally T., Pötschke P.: "Polymer-Carbon Nanotube Composites: Preparation, Properties and Applications", Woodhead Publishing, Cambridge 2011, str. 550.

[13] Anand K.A., Agarwal U.S., Joseph R.: Polymer 2006, 47, 3976. http://dx.doi.org/10.1016/j.polymer.2006.03.079

[14] Zhu Z., Wang R,, Dong Z., et al.: Journal of Applied Polymer Science 2011, 6, 3460. http://dx.doi.org/10.1002/app.33438

[15] Ramanathan T., Abdala A. A., Stankovich S., et al.: Nature Nanotechnology 2008, 3, 327. doi:10.1038/nnano.2008.96

[16] Knite M., Teteris V., Kiploka A., et al.: Sensors and Actuators A: Physical 2004, 110, 142. http://dx.doi.org/10.1016/j.sna.2003.08.006 


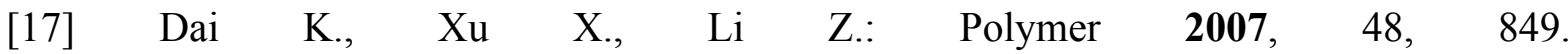
http://dx.doi.org/10.1016/j.polymer.2006.12.026

[18] Staniszewski Z., $\quad$ El Fray M.: Polimery 2016, 61, 482. dx.doi.org/10.14314/polimery.2016.482

[19] Staniszewski Z, Piegat A, Okroj W, Walkowiak-Przybylo M, Jakubowski W, Walkowiak B, Budner B, Mroz W, Sobolewski P, El Fray M. J Biomater Appl 2017, 31(10):1328-1336. doi:10.1177/0885328217706193.

[20] Chen Z., Hay J.N., Jenkins M.J.: European Polymer Journal 2012, 48, 1586. http://dx.doi.org/10.1016/j.eurpolymj.2012.06.006

[21] Baldissera A., Valério C., Basso N., et al.: Química Nova 2005, 28, 188. http://dx.doi.org/10.1590/S0100-40422005000200004.

[22] Folkes M.J.: "Processing, Structure and Properties of Block Copolymers", Springer, New York 1985, p. 29.

[23] Rabe M., Verdes D., Seeger S.: Adv Colloid Interface Sci 2011, 162, 87. doi:10.1016/j.cis.2010.12.007.

[24] Tuson H.H., Weibel D.B.: Soft Matter 2013, 9, 4368. http://dx.doi.org/10.1039/C3SM27705D

[25] Wenzel R. N.: Industrial \& Engineering Chemistry 1936, 28, 988.

http://dx.doi.org/10.1021/ie50320a024

[26] Katsikogianni M., Missirlis Y.F.: Eur Cell Mater 2004,8, 37. http://dx.doi.org/10.22203/eCM.v008a05 
[27] Campoccia D., Montanaro L., Arciola C.R.: Biomaterials 2013, 34, 8533 (2013). http://dx.doi.org/10.1016/j.biomaterials.2013.07.089

[28] Zhang X., Zhang Q., Yan T., Jiang Z., Zhang X., Zuo Y.Y.: Environ Sci Technol 2015 49, 6164. http://dx.doi.org/ 10.1021/es5050425

[29] Eberli D.: "Regenerative Medicine and Tissue Engineering - Cells and Biomaterials", InTech, Rijeka 2011.

[30] Mih J.D., Sharif A.S., Liu F., et al.: PLoS One, 2011, 6, e19929.

https://doi.org/10.1371/journal.pone.0019929 